\title{
LIDERANÇA DO ENFERMEIRO E A SUSTENTATIBILIDADE DO SISTEMA DE SAÚDE
}

\author{
Nursing leadership and sustainability of the health system
}

DOI: $10.5327 / Z 1414-4425201700040001$

A competência liderança tem sido cada vez mais exigida do enfermeiro ${ }^{1}$. Diversas razões corroboram isso, dentre elas: velocidade da informação, mudança do perfil epidemiológico da população, novas exigências do cliente interno e externo, pressões do mercado, dentre outras. Alé, disso, num mundo competitivo, com crises de diversas origens, a sustentabilidade, em seus três níveis ${ }^{2}$ - ambiental, social e econômico - ganha especial atenção dos gestores.

No centro cirúrgico, essa realidade também se faz presente. O enfermeiro preocupa-se com o uso consciente de recursos, algo que deve fazer parte da sua rotina de trabalho; e a instituição onde atua deve subsidiá-lo com políticas e procedimentos específicos para esse fim. Redução de resíduos, destino correto dos materiais, reciclagem e uso consciente são alguns conceitos que referenciam sua atuação.

O impacto social de seu trabalho também é outra inquietação. Ações desenvolvidas durante o turno e também pela instituição que promovem uma rede de bem-estar coletivo, tais como videoconferências com outros colegas da área, orientação para a equipe sob sua gestão, parcerias público -privadas, compartilhamento de informações entre diversos setores e participação em comissões especiais são alguns exemplos dessa prática.

Contudo, a sustentabilidade financeira tem ganhado destaque tendo em vista os acontecimentos do mundo político e econômico vivido neste ano no Brasil. Os enfermeiros são fundamentais para garantir que os recursos financeiros sejam corretamente utilizados. Nesse sentido, há um movimento pela busca de melhoria contínua nos processos de trabalho com a otimização de tempo e dinheiro. Diversos projetos têm sido liderados por enfermeiros do centro cirúrgico: fluxo do paciente, redução do número de cancelamentos de cirurgias, ociosidade das salas e quadro de pessoal de enfermagem dimensionado para os horários de maior movimento estão entre alguns dos muitos existentes.

A entrega dos resultados é muito esperada para que novos fluxos de trabalho aconteçam. O papel do líder é crucial ${ }^{3}$. Assim, a liderança do enfermeiro e seu constante aprendizado e aperfeiçoamento garantem que muitas metas sejam alcançadas. Autoconhecimento, plano de desenvolvimento individual, estudo, pesquisa e aprendizado prático são alguns caminhos que necessitam ser percorridos. No centro cirúrgico, há um campo fértil de oportunidades que podem favorecer a liderança desse profissional e garantir a sustentabilidade do sistema. Por isso, é necessário que o enfermeiro se aproprie do gerenciamento da unidade e exerça o seu papel como líder.

Alexandre Pazetto Balsanelli Docente Adjunto do Departamento de Administração em Serviços de Saúde e Enfermagem da Escola Paulista de Enfermagem da Universidade Federal de São Paulo (EPE-UNIFESP) - São Paulo (SP), Brasil.

\section{REFERÊNCIAS}

1. Balsanelli AP, Cunha IKO. Liderança do enfermeiro em unidade de terapia intensiva e sua relação com ambiente de trabalho. Rev Latino-Am Enferm. 2015;23(1):106-13.

2. Sachs I. Desenvolvimento: includente, sustentável, sustentado. Rio de Janeiro: Garamond; 2004. 152 p.
3. Marzagão DSL, Carvalho MM. A influência das competências comportamentais dos líderes de projetos no desempenho de projetos Seis Sigma. Rev Bras Gestão Negócios. 2016;18(62):609-32. 